\title{
Astroem para Professores e o Ensino de Matemática: Iniciação à Linguagem da Programação por meio da Robótica
}

\author{
Claudia de Oliveira Lozada1, Claudia Celeste Celestino2, Wesley Góis3
}

\author{
1Instituto de Matemática \\ Universidade Federal de Alagoas (UFAL) - Maceió, AL - Brasil \\ 2,3Centro de Engenharia, Modelagem e Ciências Sociais Aplicadas \\ Universidade Federal do ABC - Santo André, SP - Brasil \\ cld.lozada@gmail.com, claudia.celeste@ufabc.edu.br, \\ wesley.gois@ufabc.edu.br
}

\begin{abstract}
In this work we report on the importance of continuing teacher education in logic and programming language, especially given the predictions of the BNCC for Mathematics. Even if the school has resources such as a computer lab, training is necessary, and many educational resources can serve as a vehicle for programming language teaching, such as Robotics. The results with the preliminary use of Robomind proved to be satisfactory and were corroborated by the later activities with Lego NXT and Scratch, later stages in which teachers started to present a greater command of the programming language.
\end{abstract}

Resumo. Neste trabalho trazemos um relato sobre a importância da formação continuada de professores em lógica e linguagem da programação, principalmente dadas as previsões da BNCC para Matemática. Mesmo que a escola disponha de recursos como laboratório de informática, a capacitação é necessária, e muitos recursos educacionais podem servir de veículo para o ensino da linguagem da programação, como é o caso da Robótica. Os resultados acerca da utilização preliminar do Robomind mostraram-se satisfatórios e sendo corroborados pelas atividades posteriores com o Lego NXT e o Scratch, etapas posteriores nas quais os professores passaram a apresentar maior domínio da linguagem da programação.

\section{Introdução}

Com o advento da tecnologia e sua utilização como ferramenta de ensino, por meio dos diferentes dispositivos que se agrupam nas Tecnologias Digitais de Informação e Comunicação (TDICs), a didática, a metodologia, o espaço da sala de aula e os processos de ensino e aprendizagem vem sofrendo transformações. Nesse contexto tecnológico, é que se indaga sobre a importância da formação continuada e da própria formação inicial dos professores que ensinam Matemática. 
Menezes, Braga e Seimetz (2018, p. 4) apontam que o uso das TDICs no ensino de Matemática tornam as aulas mais dinâmicas, motivadoras, instigantes para alunos, criando novas relações entre o aluno e o objeto de conhecimento, o que pode, segundo os autores contribuir para diminuir o fracasso escolar. Os autores colocam ainda que na formação inicial é "preparar um profissional que enfrente os desafios educacionais de seu tempo, o que inclui os aparatos tecnológicos". Para tanto, dentre os obstáculos que apontam para a inserção das TDICs, destacamos a formação docente qualificada, políticas educacionais para sistematização das TDIC no currículo escolar e a utilização adequada desses recursos considerando-se as concepções pedagógica relativas ao seu emprego no contexto educativo.

Kalinke $(2014$, p. 25$)$ corrobora o que foi dito anteriormente afirmando que, “(...) para acompanhar essas transformações, o profissional do magistério precisa estar atento a esse novo contexto tecnológico e preparado para enfrentar as novidades com as quais se depara constantemente".

Inclusive é importante observar que o Parecer CNE/CP 009/2001 já apontava como uma das competências da formação para a atividade docente, "o uso de tecnologias da informação e da comunicação e de metodologias, estratégias e materiais de apoio inovadores". Mas, de 2001 para 2019, enfrenta-se ainda a questão de reformulação curricular das licenciaturas em Matemática e também de Pedagogia, que formam os professores que ensinam Matemática na Educação Básica, para acolher disciplinas que efetivamente conciliem teoria e prática, com atividades voltadas para $\mathrm{o}$ uso das TDICs, de modo que os futuros professores sintam-se ambientados e com subsídios para a aplicação em sala de aula. Essas ações contribuem para a inclusão digital educativa dos futuros professores, bem como implicam numa contribuição para a alfabetização digital, o letramento digital e a fluência digital, que amplificam a esfera do conhecimento especializado do conteúdo [Ball, Thames e Phelps, 2008] acerca do pensamento computacional. Além do mais, é necessário investimento para aquisição dos recursos tecnólogicos educativos para equipar as escolas públicas onde a maioria desses futuros professores atuará. O movimento de inovação curricular na Educação Básica impulsionado pela reforma do Ensino Médio que desencadeou a elaboração e publicação da Base Nacional Comum Curricular [BNCC] foi importante no sentido de valorizar o desenvolvimento do pensamento computacional. A BNCC traz como uma das competências gerais a cultura digital e como decorrentes as competências 1, 2 e 5, que inclui o pensamento computacional onde se situa a linguagem da programação.

Além do mais, a presença das empresas que trabalham com produtos educativos tecnológicos e sua exposição em feiras nas quais as escolas privadas são os seus principais públicos, e o respectivo marketing dos produtos tecnológicos educativos disseminado pelas redes sociais e canais no you tube trazendo alternativas de TDICs acessíveis e gratuitas, sobretudo, para os profissionais de escolas públicas, são estratégias que têm se constituído um cenário potencialmente motivador para a consolidação das TDICs no contexto educacional brasileiro, e certamente auxiliarão na introdução do pensamento computacional nas aulas. Nesse sentido, trazemos um relato de experiência sobre um módulo de um curso de extensão voltado para os professores da Educação Básica, que visa contribuir com a formação continuada em pensamento computacional e linguagem da programação por meio da Robótica, com o uso do Robomind. 


\section{BNCC e a Linguagem da Programação}

A Base Nacional Curricular Comum [BNCC] publicada em 2018 está estruturada em 10 competências gerais que abrangem todas as disciplinas, o que implica num ensino mais globalizado $\mathrm{e}$ afinado com as tendências curriculares atuais que envolvem $o$ desenvolvimento de habilidades socioemocionais, conhecimento num contexto tecnológico e multicultural, criatividade, cidadania, criticidade, profissionalidade e os projetos de vida, resgatando muito do que Delors (2003) colocava quando enunciou os quatro pilares da educação: aprender a ser, aprender a conviver, aprender a conhecer e aprender a fazer.

O uso das TDICs aparece na BNCC como uma competência geral na Educação Básica: "Utilizar tecnologias digitais de comunicação e informação de forma crítica, significativa, reflexiva e ética nas diversas práticas do cotidiano (incluindo as escolares) ao comunicar, acessar e disseminar informações, produzir conhecimentos e resolver problemas" [Brasil, 2018, p. 09]. Decorre da ascensão do desenvolvimento tecnológico e presença de dispositivos tecnológicos e maior acesso a eles, assim como a disseminação de um grande volume de informações e dados por meio da internet e formas mais dinâmicas de ser comunicar trazidas pelas redes sociais e tecnologias móveis. O algoritmo ganhou uma enorme importância na Era da Big Data e se tornou frequente em ações cotidianas, como por exemplo, a pesquisa de preços de um determinado produto por meio de buscadores de sites, que além de selecionar o menor preço, conseguem apontar a preferência do consumidor por outros produtos por meio da inteligência artificial. Inclusive a BNCC, para o Ensino Médio, no itinerário formativo "Matemática e suas Tecnologias" recomenda que se façam arranjos curriculares que permitam estudos em "robótica, automação, inteligência artificial, programação e jogos digitais" [Brasil, 2018, p. 477].

Nas competências gerais 1 e 2 respectivamente, a BNCC cita a valorização e utilização dos conhecimentos historicamente construídos no mundo digital e a criação de soluções tecnológicas [Brasil, 2018, p. 09], o que implica imersão, domínio dos conhecimentos computacionais e habilidades e competências para aplicação dos recursos digitais. Por outro lado, a utilização da tecnologia aparece como uma competência do ensino de Matemática do Ensino Fundamental: "Utilizar processos e ferramentas matemáticas, inclusive tecnologias digitais disponíveis, para modelar e resolver problemas cotidianos, sociais, de outras áreas do conhecimento, validando estratégias e resultados [Brasil, 2018, p. 267].” Dessa forma, a escola e os professores devem viabilizar o ensino de Matemática atrelado à resolução de problemas e ao desenvolvimento do pensamento computacional e utilização das TDICs.

Para a utilização da tecnologia no dia a dia, é preciso que o aluno compreenda o mecanismo de funcionamento dos dispositivos e sua linguagem específica. A linguagem da programação mostra-se como um desdobramento do pensamento computacional decorrente das tecnologias digitais mencionadas na $\mathrm{BNCC}$, o que implica não só no letramento digital, mas também na representação de dados, nos algoritmos, na codificação e abstração. Assim, as tecnologias na BNCC não são apenas ferramentas de aprendizagem de conteúdos, mas também dispositivos com os quais os alunos se deparam e utilizam em seu cotidiano e que exigem certo domínio. Dessa forma, o currículo - posto em ação - previsto pela BNCC, demandará não só recursos para equipar as escolas, mas também a capacitação docente, seja pelas secretarias de 
educação ou pelas universidades por meio de cursos de atualização, extensão ou pósgraduação lato sensu.

\section{Formação continuada: o Curso de Extensão Astroem para Professores}

O curso de extensão Astroem para Professores foi realizado nos meses de junho e julho de 2018 com carga horária de 40h. Foi promovido pela Pró-Reitoria de Extensão E Cultura da Universidade Federal do ABC (UFABC) e executado pela equipe do Projeto Astroem e convidado externo.

O Projeto Astroem foi idealizado em 2013 por pesquisadores da Engenharia Aeroespacial da UFABC, sendo ofertado anualmente na modalidade presencial para alunos da Educação Básica (com os eixos formativos em Astronáutica, Aeronáutica, Mecânica Aplicada e Astronomia) e pela primeira vez foi ofertado para professores também na modalidade presencial contemplando as temáticas de Astronáutica, Aeronáutica, Scratch e Robótica, estas últimas decorrentes da previsão da inserção da linguagem da programação no currículo pela BNCC. O Scratch e a Robótica abrangiam noções de liguagem da programação, o primeiro por blocos e a segunda por meio do léxico (com as funções matemáticas e palavras reservadas) e a gramática (com seus operadores).

No entanto, foi necessário preliminarmente ensinar as noções de lógica básica, álgebra booleana, para depois abordar algoritmos, programação e especificamente a Robótica, uma vez que os robôs necessitavam de programação para se movimentar, assim como o personagem gato do Scratch. Por sua vez, muitos dos professores não possuíam noções de lógica e nem de linguagem da programação. Como material de apoio foi fornecida uma apostila com o conteúdo teórico e os exercícios.

O curso foi estruturado em duas partes: teórica e prática, sendo que a teórica além dos conhecimentos específicos das temáticas, também possuía fundamentos teóricos sobre a utilização das TDICs na Educação. $O$ curso foi ministrado no laboratório de informática da Universidade Federal do ABC, Campus Santo André, em 4 sábados, com carga horária total de 32 horas.

Um dos recursos utilizados no curso foi o software Robomind. A pertinência desta ferramenta educativa é auxiliar na introdução da linguagem da programação por meio da Robótica, utilizando o léxico e a gramática, com o ensino dos movimentos básicos do robô que são ver, pegar, andar e pintar. Em seguida, foram propostos desafios na movimentação do robô dentro de um cenário com obstáculos. Após a aula, aplicamos um questionário com a finalidade de verificar se os professores aprenderam os comandos básicos por meio da linguagem da programação e se acharam que a ferramenta Robomind era viável nas aulas. Sete professores responderam ao questionário que possuía 12 questões, sendo 3 fechadas e as demais questões abertas.

A primeira questão era a seguinte: "Para que serve a lógica? Qual a importância de conhecê-la/dominá-la considerando os avanços tecnológicos?" Dos doze alunos matriculados no curso, 7 estavam presentes nesta aula e deram as seguintes respostas: 


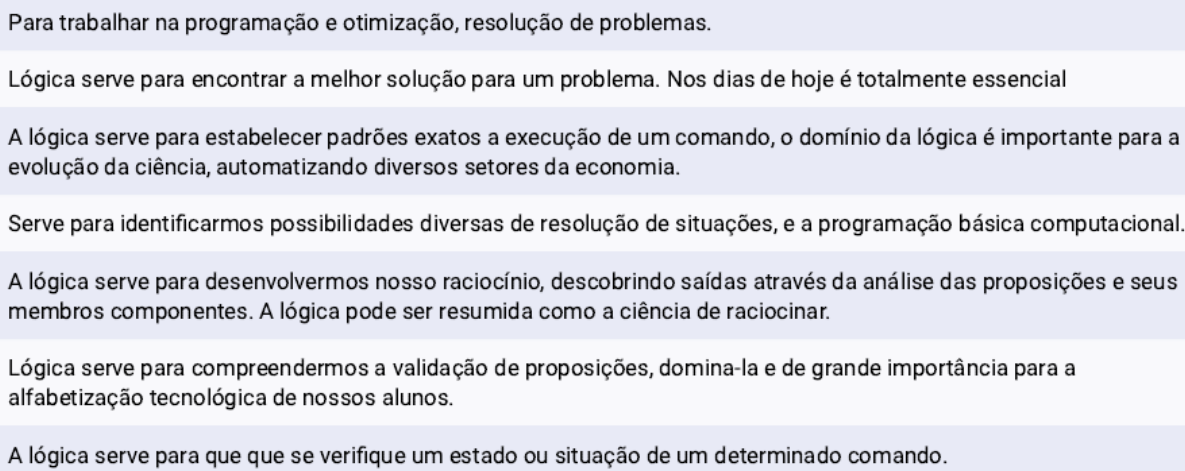

Figura 1. Respostas da $1^{\mathrm{a}}$ questão

Três professores ligaram a lógica à resolução de problemas, dois à execução de comandos, um deles ao raciocínio lógico e outro à alfabetização científica e tecnológica. Portanto, a maioria dos professores presentes no curso atrelou a lógica à resolução de problemas, sendo que as compreensões expressas pelos demais professores são complementares à noção que se tem de lógica, portanto, as respostas se complementam e para uma abordagem inicial podem ser consideradas satisfatórias.

$\mathrm{Na} 2^{\mathrm{a}}$ questão, colocou-se uma questão usual de lógica, problematizando: "Leonardo, Caio e Márcio são considerados suspeitos de praticar um crime. Ao serem interrogados por um delegado, Márcio disse que era inocente e que Leonardo e Caio não falavam a verdade. Leonardo disse que Caio não falava a verdade, e Caio disse que Márcio não falava a verdade. A partir das informações dessa situação hipotética, é correto afirmar que: (A) os três rapazes mentem. (B) dois rapazes falam a verdade. (C) nenhuma afirmação feita por Márcio é verdadeira. (D) Márcio mente, e Caio fala a verdade. (E) Márcio é inocente e fala a verdade." Os resultados foram estes mostrados na figura 2: apenas $14,3 \%$, ou seja, um docente, acertou esta questão, o que implica em pouco contato dos docentes com questões de lógica.

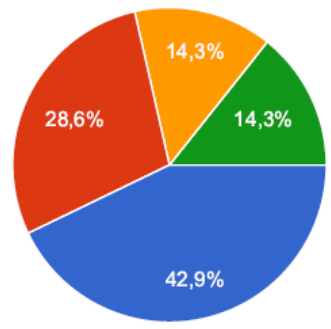

os três rapazes mentem

dois rapazes falam a verdade.

nenhuma afirmação feita por Márcio é verdadeira.

Márcio mente, e Caio fala a verdade.

Márcio é inocente e fala a verdade.

Figura 2. Respostas da $2^{\mathrm{a}}$ questão

Nas questões 3 e 4 solicitou-se aos docentes que escrevessem os scripts para movimentar o robô em determinado cenário, representado abaixo pela figura 3 . No primeiro, deveriam escrever o script para que o robô saísse do labirinto e chegasse ao objeto, e no segundo deveriam escrever o script para instruir o robô a pintar o caminho percorrido até o objeto de preto, não pintando os pontos brancos. 


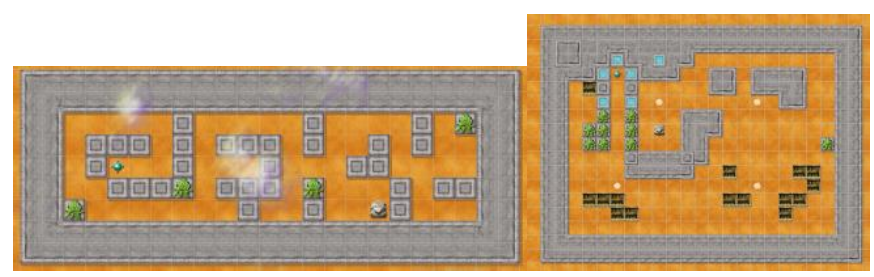

Figura 3. Telas da $3^{a}$ e $4^{a}$ questão

Apresentamos aqui alguns scripts relativos à questão (figura 4), lembrando que há escritas dos scripts do Robomind que são equivalentes e exercem a mesma função, e que seria necessário que escrevessem lembrando que o script decorre da movimentação do robô e isto deveria ser realizado como forma de comprovação de que a movimentação estaria correta.

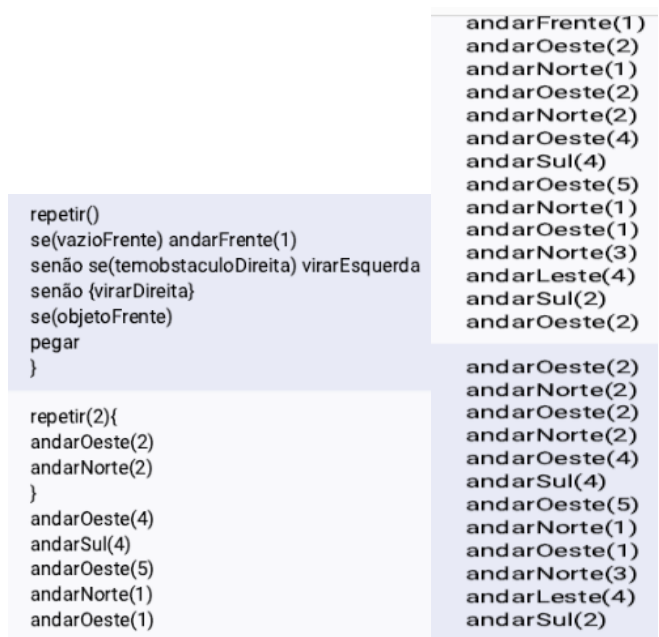

\begin{abstract}
Andar a frente(1) se obstáculo a frente, virar esquerda. Andar a frente (3). Andar norte (1) se obstáculo a frente norte (3) virar esquerda. Andar Sul (4), Andar oeste(6) se obstáculo a frente virar esquerda. AndarNorte (3) Andar leste (4), Andar sul (3) andar frente (1).

virarEsquerda()andarFrente(2)virarDireita(0andarFrente(2)virarEsquerda()andarFrente(2)virarDireita(0andarFrente(2)vira rEsquerda()andarFrente(4)virarEsquerda()andarFrente(4)virarDireita()andarFrente(5)virarDireita()andarFrente(1)virarEs querda()andarFrente(1)virarDireita()andarFrente(3)virarDireita()andarFrente(4)virarDireita()andarFrente(2)virarDireita()a ndarFrente(2)
\end{abstract}

Figure 4. Respostas com os scripts $3^{\mathrm{a}}$ questão

Percebe-se que alguns têm dificuldades em escrever os comandos e estruturas de repetição, outros utilizam os condicionais, alguns escreveram como se estivessem digitando frases da língua portuguesa corrente misturadas com comandos, assim como outros não observaram a questão de se escrever cada comando em uma linha. $\mathrm{Na}$ questão 4, os scripts eram mais elaborados e algumas dificuldades semelhantes à questão 3 no que diz respeito à escrita foram observadas, inclusive um dos docentes não conseguiu escrever um dos comandos (figura 5): 


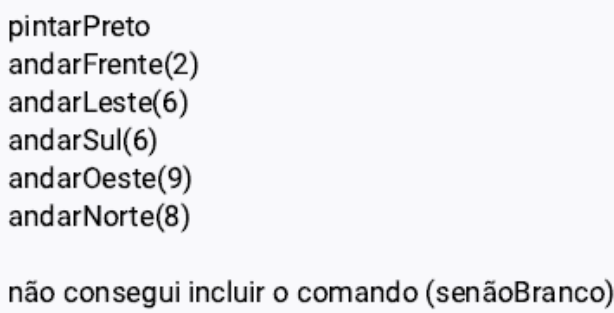

Figura 5. Resposta com os scripts $4^{\mathrm{a}}$ questão

Na questão seguinte, solicitou-se que propusessem uma atividade utilizando os mapas (cenários) fornecidos colocando os comandos. A maioria apontou o mapa usado e relatando as ações do robô, mas apenas um indicou o script do comando. Percebe-se que a maioria não compreendeu o que a questão pediu e/ou não conseguiu de fato escrever os comandos e deixou relatada a ação do robô, como vemos a seguir na figura 6:

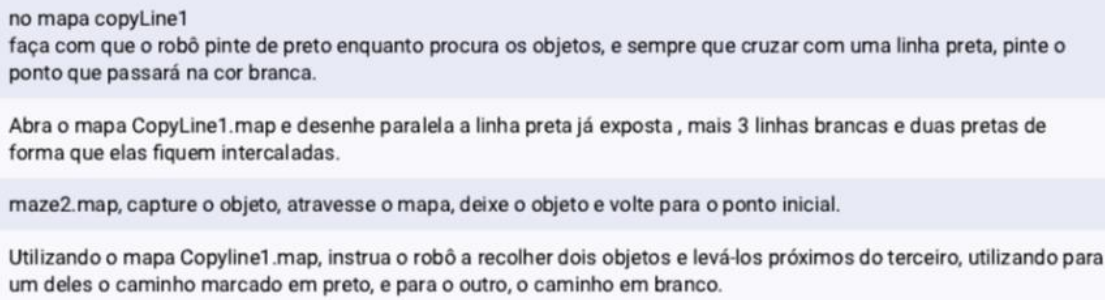

Castle.map - Contornar o mapa pintando cada sentido de branco e preto realizando o revezamento das cores. pintarPreto

Figura 6. Resposta da $5^{a}$ questão

$\mathrm{Na}$ questão seguinte perguntou-se: "Qual a importância e relevância da abordagem da Lógica Básica de Programação para o ensino básico?" Apenas 6 dos participantes responderam como se pode ver na figura 7:

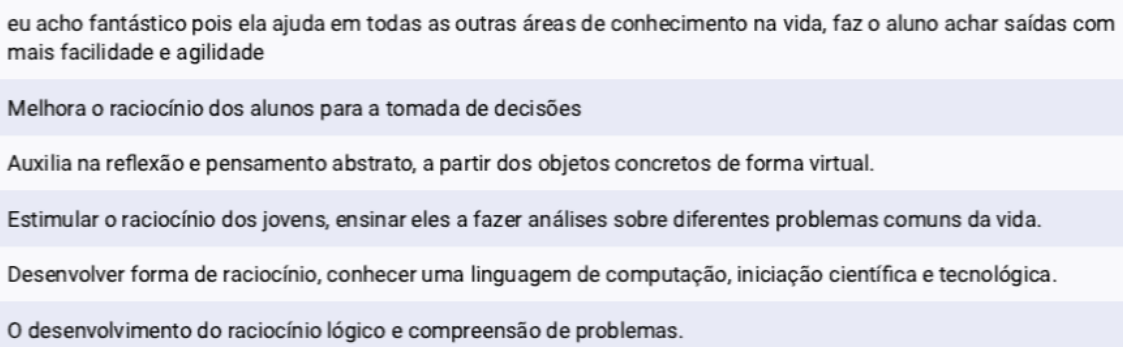

Figura 7. Resposta da 6⿳a questão 
A maioria das respostas atrela a importância da lógica básica de programação na Educação Básica ao desenvolvimento do raciocínio lógico, importante no rol de competências e habilidades matemáticas, previstas na BNCC.

Na questão seguinte (questão 7), perguntou-se quais adaptações eles fariam nas tarefas do Robomind. A maioria afirmou que não faria adaptações nas atividades propostas, e um deles apontou a necessidade de se aprofundar mais a respeito do Robomind. $\mathrm{Na} 8^{\mathrm{a}}$ questão perguntou-se como a metodologia utilizada no curso, principalmente nas explicações e no momento de prática com o programa do Robomind, poderia auxiliar na construção de uma proposta didático-pedagógica. As respostas dadas estão ligadas às aulas mais dinâmicas e motivação, considerando-se que um dos docentes pontuou algo importante que é a graduação das problematizações e questionamentos propostos nas atividades, de modo que vão dando forma ao pensamento relacionado à lógica da programação, aspecto fundamental, uma vez que muitos alunos podem considerar inicialmente a lógica da programação algo muito abstrato, e pouco se envolverem com as atividades, e com a graduação do nível das atividades esse fator impeditivo poderá ser descartado. Vejamos as respostas dadas expostas pela figura 8:

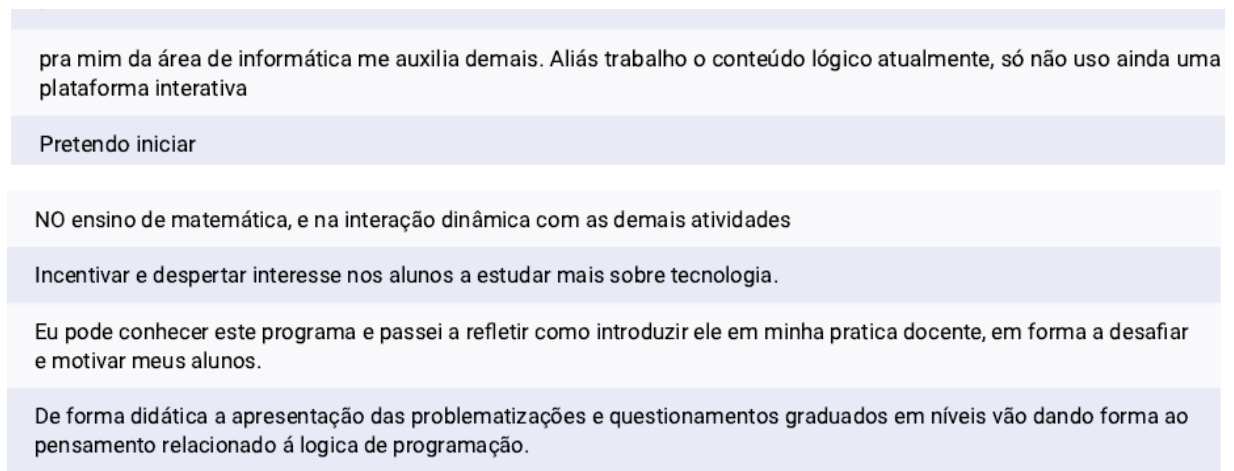

Figura 8. Resposta da $8^{a}$ questão

$\mathrm{Na} 9 \mathrm{a}$ questão, indagou-se os docentes se consideravam viável o uso do Robomind como ferramenta de ensino nas aulas da Educação Básica, e 85,7\% considerou viável, ou seja, apenas um dos 6 respondentes considerou "depende", e sua justificativa foi apresentada na questão seguinte na qual se pediu para justificar a viabilidade ou não, considerando a escola onde o professor atua (figura 9):

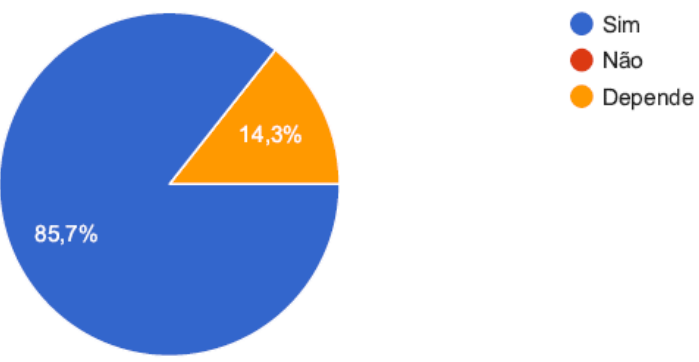

Figura 9. Resposta da 9ª questão 
A justificativa apresentada pelo docente sobre o "depende" em relação à viabilidade é direcionada para o nível de compreensão dos alunos em relação às questões de localização e Matemática, ou seja, movimentação virtual do robô num cenário depende de comandos que podem ser um tanto abstratos para os alunos, ou seja, são diferentes de se movimentar um objeto num espaço concreto e real. A isto, juntamse dificuldades que podem ser oriundas das defasagens dos alunos em conteúdos matemáticos e o não contato com lógica. Abaixo na figura 10, estão as respostas:

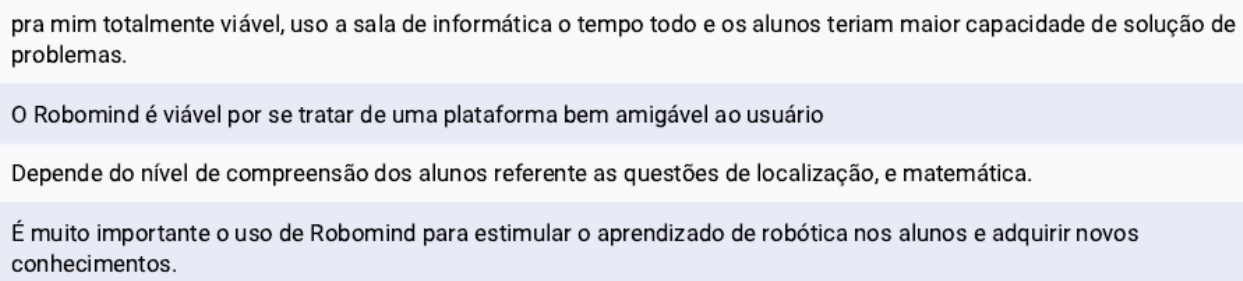

Minha escola possui um laboratório de informática bom que poderá ser utilizado com minhas turmas a desenvolver o raciocínio lógico, construção de estratégias colaborativas e ate em competições.

Viável pois devolve ao aluno a possibilidade de se tornar um ser protagonista.

\section{Figura 10. Resposta da $11^{a}$ questão}

$\mathrm{Na}$ penúltima questão, pediu-se para os docentes indicarem com quais disciplinas eles fariam um trabalho interdisciplinar com o Robomind e porque a interdisciplinaridade é importante nas práticas pedagógicas. As respostas dadas foram estas (figura 11):

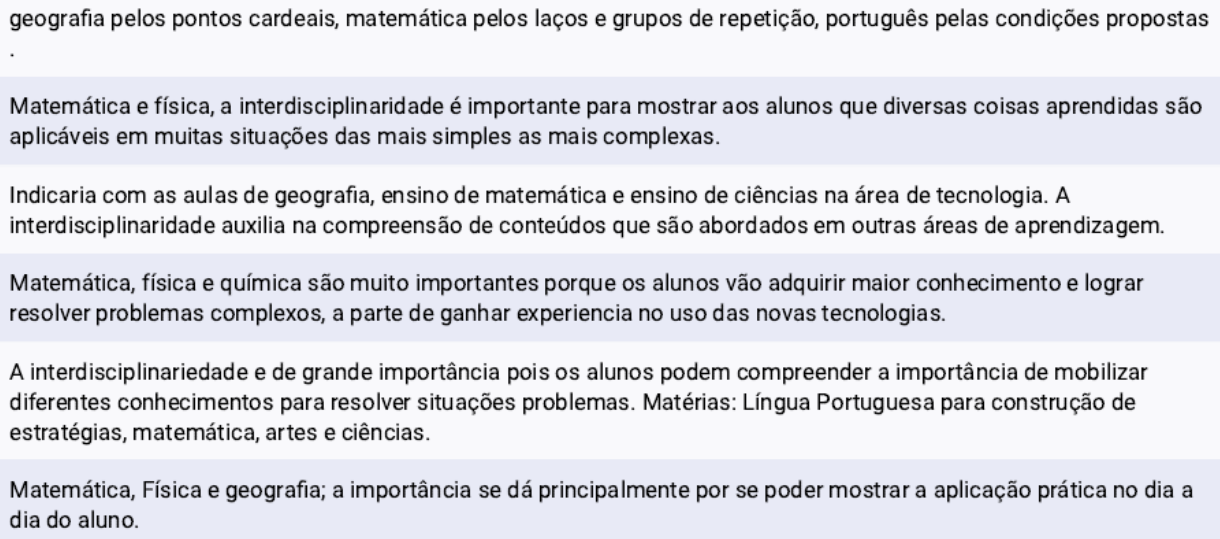

Figura 11. Resposta da $12^{\mathrm{a}}$ questão

Todos os docentes conseguiram indicar disciplinas com quais fariam interdisciplinaridade, mas apenas três deles justificaram o porquê ela é importante nas práticas pedagógicas, relacionando em geral com a aprendizagem do conteúdo aplicado às outras áreas do conhecimento e mobilização de diversos conhecimentos.

Por fim, indagou-se quais foram as dificuldades encontradas na execução das atividades propostas com o Robomind, sendo que dois afirmaram não ter dificuldade e os demais atrelaram em sua maioria dificuldades em relação aos comandos, o que demonstra a necessidade de se ofertar mais cursos de formação continuada e se incluir 
na formação inicial dos professores que ensinam Matemática, a lógica e a linguagem da programação. Vejamos as respostas dadas expostas na figura 13:

estabelecer a programação mais compacta para a execução do robô
nenhuma
A dificuldade foi em desenvolver o raciocínio lógico
Habilidade prática no início. E pensar sobre facilidade que os comandos podem oferecer.
Nehuma
Eu não lembrei o funcionamento do comando se () senão
A lógica e falta de conhecimento dos códigos.

Figura 13. Resposta da 13ª questão

\section{Conclusão}

Consideramos a participação dos docentes neste curso de extensão de extrema importância, assim como os resultados mostram-se satisfatórios com o uso do Robomind, sendo que nos módulos seguintes com o Lego NXT e Scratch, os docentes apresentaram maior familiarização e domínio da linguagem da programação. Os comandos do Robomind são de fácil compreensão e necessitam de maior exploração por parte do usuário a fim de fixá-los. É uma forma lúdica de abordar a linguagem da programação por meio da Robótica, o que torna as aulas mais dinâmicas e interativas.

\section{Referências}

Ball, D.; Thames, M. H. and Phelps, G. (2008). "Content Knowledge for Teaching: What makes it special?” In: Journal of Teacher Education, pages 389-407.

Brasil (2018). "Base Nacional Comum Curricular", http://basenacionalcomum.mec.gov.br/images/BNCC_EI_EF_110518_versaofinal_si te.pdf, Agosto.

Brasil (2001). "Parecer CNE/CP 9/2001: diretrizes curriculares nacionais para a formação de professores da educação básica, em nível superior, curso de licenciatura", de graduação plena, http://portal.mec.gov.br/cne/arquivos/pdf/009.pdf, Junho.

Delors, J. (2003). "Educação: um tesouro a descobrir”, Cortez, São Paulo.

Kalinke, M. A. (2014). "Tecnologias no Ensino: a linguagem matemática na web", CVR, Curitiba.

Menezes, J. E., Braga, M. D. e Seimetz, R. (2018). "O ensino na licenciatura em matemática mediado pela TDIC: opiniões e perspectivas de alunos", http://cietenped.ufscar.br/submissao/index.php/2018/article/download/725/601/, Junho. 